\title{
The effects of band exercise using proprioceptive neuromuscular facilitation on muscular strength in lower extremity
}

\author{
Hyun-Seung Rhyu', Su-Hyun Kim² ${ }^{2}$ Hye-Sang Park ${ }^{3, *}$ \\ 'Department of Sports Health Medicine, College of Health Science, Jungwon University, Geosan-gun, Chungcheongbuk-do, Korea \\ ${ }^{2}$ Department of Physical Education, Graduate School, Dankook University, Seoul, Korea \\ ${ }^{3}$ Department of Sports Health Management, University of Suwon, Hwaseong, Korea
}

The purpose of this study was to examine whether a six-week elastic band exercise program using proprioceptive neuromuscular facilitation (PNF) can increase isotonic strength of abductor muscles in the lower extremity. Twenty-eight healthy students from $S$ university were divided into an experimental group and control group. Each group was participated in pre and post-measurement in isotonic strength using an isotonic analyzer, En-treeM. Experimental group performed elastic band exercise using PNF pattern for a six-weeks, in contrast, control group did not take any exercise. In the results of this study, isotonic strength measurements of abductor muscles in lower extremity in experimental group were significantly different after exercise, but control group did not show any significant changes. Therefore, we hope that resistive exercise would be very valuable for healthy people as well as the old people with weakened muscle strength.

Keywords: En-treeM, Isotonic strength, Proprioceptive neuromuscular facilitation, Elastic band

\section{INTRODUCTION}

Enhancement of the muscular strength delays the process of physical functioning degradation, and it is also an essential component in enjoying outdoor activities with minimal stress or feeling of lethargy. Moreover, an appropriate enhancement of muscular strength lowers the outbreak of back pain as well as decreases the risk of injuries in the skeletal muscle system. As walking activities were reduced with the development of technologies and widespread driving culture, muscular strength experiences has been declined. As continuous lowering of muscular strength, the abductor of the lower limb at the side that supports weight while walking becomes weak. This may cause the progressive abnormal pelvic tilt and swinging of the trunk, which is described as the Trendelenburg gait pattern (David, 2008).
Recently, variety of measurement method has been introduced to examine the enhancement of muscular strength. Among such measures, the elastic band exercise promotes muscular strength without burdening of the weakened muscles. Elastic bands, either a band or tube made from rubber, have been used in the medical scene such as hospitals for rehabilitation conditioning. However, nowadays it is also widely used in normal households, sports training fields and by seniors due to its lightness, flexibility and ease of controlling the resistance intensity and direction of its loading properties. Also, it enables the training following the body's movement; so it is appropriate for the muscular strength training which applies the principle of proprioceptive neuromuscular facilitation (PNF).

The PNF is a mode to stimulate the body's proprioceptive system to promote normal response with its unique spiral movement. Even weakened muscles can work more effectively with the boost
${ }^{*}$ Corresponding author: Hye-Sang Park

Department of Sports Health Management, University of Suwon, 17 Wauan-gil, Bongdam-eup, Hwaseong 445-743, Korea

Tel: +82-31-229-8103, Fax: +82-31-229-8103, E-mail: wini-phs@hanmail.net

Received: February 13, 2015 / Accepted: February 22, 2015
This is an Open Access article distributed under the terms of the Creative Commons Attribution Non-Commercial License (http://creativecommons.org/licenses/by-nc/3.0/) which permits unrestricted non-commercial use, distribution, and reproduction in any medium, provided the original work is properly cited. 
of an antagonistic muscle compared to when they operate independently. Therefore, PNF is utilized as a part of the rehabilitation designed for those who have weakened muscle or joint functionalities. The number of PNF techniques applied enhances the muscle strengthening properties (Hyunseung et al., 2014).

Clinically, the isotonic methodologies and equipment such as the elastic bands have been used for their capabilities of gradual increment of muscle resistance and muscle endurance. However, the measurement of the isotonic muscular strengths had not been conducted due to the lack of the appropriate measuring apparatus. On this background, this current study explores the effectiveness of the elastic band exercise based on the PNF pattern on isotonic muscular strength of the hip joint abductor using the isotonic muscular strength measuring apparatus, EN-TreeM. Through the study, we expect to find the effective increasing condition in muscular strength enhancement with the application of the principle PNF and introduce the easy-to-use elastic band for effective isotonic muscle strength which is often discussed in improvement of muscular strength in lower extremities.

\section{MATERIALS AND METHODS}

\section{Participants}

Twenty-eight male and female students from S university were equally divided into an experimental group and a control group. Each group consisted of fourteen individuals; seven males and seven females within each group. No participants had a reported history of illness in the nervous system, muscle system or skeletal system. No participates were participated in a specific exercise program. Additionally, all participants were right-dominant (Table 1).

\section{Experimental procedures}

\section{Elastic band exercise}

With the elastic band (Hygienic Corporation, Akron, Ohio, USA), the experimental group participated in six-week isotonic resistance program while the control group was prevented from participating in any specific exercise program other than the normal

Table 1. Physical characteristics of the subjects

\begin{tabular}{lrrrrr}
\hline & \multicolumn{2}{c}{ Control group $(\mathrm{n}=14)$} & & \multicolumn{2}{c}{ Exercise group $(\mathrm{n}=14)$} \\
\cline { 2 - 3 } & Male $(\mathrm{n}=7)$ & Female $(\mathrm{n}=7)$ & & Male $(\mathrm{n}=7)$ & Female $(\mathrm{n}=7)$ \\
\hline Age $(\mathrm{yr})$ & $26.14 \pm 2.19$ & $21.57 \pm 1.90$ & & $27.14 \pm 5.87$ & $24.43 \pm 2.94$ \\
Height $(\mathrm{cm})$ & $176.00 \pm 4.80$ & $164.29 \pm 2.06$ & & $176.43 \pm 6.92$ & $164.14 \pm 3.13$ \\
Weight $(\mathrm{kg})$ & $74.00 \pm 4.24$ & $54.14 \pm 5.49$ & & $69.14 \pm 5.55$ & $54.86 \pm 2.73$ \\
\hline
\end{tabular}

Values are means $\pm S D$. daily activities. The baseline exercise intensity was set by measuring the one repetition maximum (1RM) on the non-dominant side abductor of the hip joint of the experimental group. We followed the indirect 1RM measurement procedure recommended by the Korea Institute of Sports Science (1999) for the isotopic measurement apparatus. First the maximum weight of hip joint to conduct abduction in a full range of motion within ten times was documented, and the $1 \mathrm{RM}$ was estimated by using the following formula:

$$
\begin{aligned}
& \mathrm{W} 1=\mathrm{W} 0+\mathrm{W} 0 \times 0.025 \times \mathrm{R} \\
& \mathrm{W} 1: 1 \mathrm{RM}(\mathrm{kg}) \\
& \text { W0: the weight of enabling less than } 10 \text { times of full range } \\
& \text { motion }
\end{aligned}
$$

$\mathrm{R}$ : the number of motions based on W0

The color of the band was assigned as so 50-70 percent of the estimated 1RM became the maximum tension at the hip abductor and the stretching rate was calculated. The power generated by the band was determined by the extent of the band stretch.

Because the study involves a PNF type lower extremity exercise, we estimated the band's coefficient of extension based on the full range of motion for each individual with the equation of (extended length-stabilized length)/stabilized length $\times 100$. The bands, with the resulted stabilized length marked, were distributed to the experimental group to conduct the six-week isotonic exercise program.

The flexible band exercise was conducted in the natural laying-down position, with the elastic band positioned at the back, putting the band at the shoulder grabbing one end of the band with one hand while connecting the other end of the band and fixing the band to the non-dominant foot. Then, the isotonic exercise of the lower extremities was conducted in a PNF pattern movement with the hip extension-abduction-internal rotation movement while stretching the knee joint. Under the PNF exercise, the starting positions of the lower extremities areas follow: the hip joint is bent, internally rotated and externally rotated; the knee joint is bent; the ankle joint is dorsiflexed and introverted; and the toes are extended. On the other hand, the ending positions are: the knee joint is bent; the hip joint is bent, externally rotated and internally rotated; the knee joint is stretched, the ankle joint is plantar flexed and extroverted, and the toes are bent (Bongoh et al., 2013). One set of the elastic band exercise consisted of ten repetitions with one minute rest between each set. During the week one and two; three sets of the exercise were conducted with resistance at 50 percent of the estimated 1RM of hip abductor. In weeks 
three and four; five sets were conducted at 70 percent of resistance of the 1RM, and in weeks five and six; seven sets were conducted with at 70 percent of the 1RM. All exercises were conducted four times a week for a total of six weeks.

\section{Muscular strength assessment}

The variables for the isotonic muscular strength were derived using the isotonic muscular strength measuring apparatus ENTreeM (isotonic exercise \& evaluation system, Enfaf-Nonius Corp., Holland). Both the experimental and control groups conducted the hip abductor reps with the $8 \mathrm{~kg}$ loading for $40 \mathrm{sec}$ with the maximum velocity. The assessment was conducted at pre and post workout at the same measurement of time and condition.

\section{Statistical analyses}

The SPSS statistical package (ver. 12.0) was used to estimate the means and standard deviation of each variable. The two-way ANOVA with repeated measurements were conducted to verify the effectiveness of the band exercise, under which the difference of the means at pre and post workout were tested $(P<0.05)$.

\section{RESULTS}

\section{Peak power}

As a result of the elastic band exercise based on the PNF pattern, the maximum explosive muscular strength was $56.13 \mathrm{~W}$ (pre) and $61.16 \mathrm{~W}$ (post) at concentric contraction, $59.50 \mathrm{~W}$ (pre) and 75.70 W (post) at eccentric contraction, with the significant difference between the control group and experimental group $(P<0.05)$. Therefore, the PNF-based band exercise improved the peak explosive muscular power in the isotonic contraction of the abductor of lower extremities (Table 2).

\section{Average peak power}

As a result of the elastic band exercise based on the PNF pattern, the maximum mean explosive muscular strength was $44.4 \mathrm{~W}$ (pre) and 50.69 W (post) at concentric contraction, $42.21 \mathrm{~W}$ (pre) and $49.16 \mathrm{~W}$ (post) at eccentric contraction, with a significant difference between the control group and experimental group $(P<0.05)$. Therefore, the PNF-based band exercise improved the peak explosive muscular power in the isotonic contraction of the abductor of lower extremities (Table 2).

\section{Average power}

As a result of the elastic band exercise based on the PNF pattern,
Table 2. The exchange of muscular strength in lower using band exercise I

\begin{tabular}{llllll}
\hline Variables & Group & Contraction type & Pre & Post & \multicolumn{1}{c}{$P$} \\
\hline Peak power & Con. & Concentric & $53.78 \pm 17.57$ & $56.00 \pm 19.94$ & 0.478 \\
(W) & & Eccentric & $54.92 \pm 13.59$ & $54.13 \pm 13.46$ & 0.869 \\
& Exe. & Concentric & $56.13 \pm 17.38$ & $61.16 \pm 16.52$ & $0.032^{*}$ \\
& & Eccentric & $59.50 \pm 16.99$ & $75.70 \pm 29.44$ & $0.001^{*}$ \\
Average & Con. & Concentric & $42.68 \pm 14.24$ & $45.89 \pm 17.08$ & 0.243 \\
peak power & & Eccentric & $40.30 \pm 11.43$ & $38.51 \pm 11.37$ & 0.566 \\
(W) & Exe. & Concentric & $44.40 \pm 12.99$ & $50.69 \pm 13.68$ & $0.005^{*}$ \\
& & Eccentric & $42.21 \pm 12.44$ & $49.16 \pm 14.88$ & $0.008^{*}$ \\
Average power & Con. & Concentric & $21.60 \pm 7.64$ & $23.45 \pm 9.10$ & 0.128 \\
(W) & & Eccentric & $19.84 \pm 5.84$ & $20.30 \pm 7.35$ & 0.738 \\
& Exe. & Concentric & $23.57 \pm 7.57$ & $28.60 \pm 8.42$ & $0.001^{*}$ \\
& & Eccentric & $23.01 \pm 6.93$ & $27.47 \pm 8.94$ & $0.013^{*}$ \\
Peak velocity & Con. & Concentric & $1.20 \pm 0.35$ & $1.25 \pm 0.40$ & 0.447 \\
(m/s) & & Eccentric & $1.17 \pm 0.06$ & $1.18 \pm 0.07$ & 0.830 \\
& Exe. & Concentric & $1.25 \pm 0.08$ & $1.35 \pm 0.08$ & $0.022^{*}$ \\
& & Eccentric & $1.26 \pm 0.33$ & $1.51 \pm 0.36$ & $0.001^{*}$ \\
\hline
\end{tabular}

Values are means $\pm S D$.

${ }^{*} P<0.05$.

the average power was $23.57 \mathrm{~W}$ (pre) and $28.6 \mathrm{~W}$ (post) at concentric contraction; $23.01 \mathrm{~W}$ (pre) and 27.47 W (post) at eccentric contraction, with a significant difference between the control group and experimental group $(P<0.05)$. Therefore, the PNFbased band exercise improved the average power in the isotonic contraction of the abductor of lower extremities (Table 2).

\section{Peak velocity}

As a result of the elastic band exercise based on the PNF pattern, the peak velocity was $1.25 \mathrm{~m} / \mathrm{s}$ (pre) and $1.35 \mathrm{~m} / \mathrm{s}$ (post) at concentric contraction, $1.26 \mathrm{~m} / \mathrm{s}$ (pre) and $1.51 \mathrm{~m} / \mathrm{s}$ (post) at eccentric contraction, with a significant difference between the control group and experimental group $(P<0.05)$. Therefore, the PNF-based band exercise improved the peak velocity in the isotonic contraction of the abductor of lower extremities (Table 2).

\section{Average peak velocity}

As a result of the elastic band exercise based on the PNF pattern, the average peak velocity was $1.02 \mathrm{~m} / \mathrm{s}$ (pre) and $1.14 \mathrm{~m} / \mathrm{s}$ (post) at concentric contraction, $0.95 \mathrm{~m} / \mathrm{s}$ (pre) and $1.10 \mathrm{~m} / \mathrm{s}$ (post) at eccentric contraction, with a significant difference between the control group and experimental group $(P<0.05)$. Therefore, the PNFbased band exercise improved the average peak velocity in the isotonic contraction of the abductor of lower extremities (Table 3).

\section{Peak force}

As a result of the elastic band exercise based on the PNF pat- 
tern, the peak force was $55.64 \mathrm{~N}$ (pre) and $59.64 \mathrm{~N}$ (post) at concentric contraction, $60.79 \mathrm{~N}$ (pre) and $65.20 \mathrm{~N}$ (post) at eccentric contraction, with a significant difference between the control group and experimental group $(P<0.05)$. Therefore, the PNFbased band exercise improved the peak force in the isotonic contraction of the abductor of lower extremities (Table 3).

\section{Average peak force}

As a result of the elastic band exercise based on the PNF pattern, the average peak force was $51.55 \mathrm{~N}$ (pre) and $54.65 \mathrm{~N}$ (post) at concentric contraction, $53.3 \mathrm{~N}$ (pre) and $55.81 \mathrm{~N}$ (post) at eccentric contraction, with significant difference between the control group and experimental group $(P<0.05)$. Therefore, the PNF-based band exercise improved the average peak force in the isotonic contraction of the abductor of lower extremities (Table 3).

\section{Total work}

As a result of the elastic band exercise based on the PNF pattern, the total work was $454.43 \mathrm{~J}$ (pre) and $553 \mathrm{~J}$ (post) at concentric contraction, $449.57 \mathrm{~J}$ (pre) and $548.36 \mathrm{~J}$ (post) at eccentric contraction, with a significant difference between the control group and experimental group $(P<0.05)$. Therefore, the PNFbased band exercise improved the total work in the isotonic contraction of the abductor of lower extremities (Table 3).

Table 3. The exchange of muscular strength in lower using band exercise II

\begin{tabular}{|c|c|c|c|c|c|}
\hline Variables & Group & $\begin{array}{c}\text { Contraction } \\
\text { type }\end{array}$ & Pre & Post & $P$ \\
\hline \multirow{4}{*}{$\begin{array}{l}\text { Average peak } \\
\text { velocity } \\
(\mathrm{m} / \mathrm{s})\end{array}$} & \multirow{2}{*}{ Con. } & Concentric & $0.98 \pm 7.64$ & $1.05 \pm 0.36$ & 0.267 \\
\hline & & Eccentric & $0.90 \pm 0.06$ & $0.88 \pm 0.07$ & 0.679 \\
\hline & \multirow[t]{2}{*}{ Exe. } & Concentric & $1.02 \pm 0.07$ & $1.14 \pm 0.07$ & $0.007^{*}$ \\
\hline & & Eccentric & $0.95 \pm 0.25$ & $1.10 \pm 0.29$ & 0.010 \\
\hline \multirow{4}{*}{$\begin{array}{l}\text { Peak force } \\
\text { (N) }\end{array}$} & \multirow[t]{2}{*}{ Con. } & Concentric & $54.58 \pm 5.08$ & $55.35 \pm 5.90$ & 0.499 \\
\hline & & Eccentric & $60.14 \pm 1.14$ & $58.49 \pm 0.95$ & 0.298 \\
\hline & \multirow[t]{2}{*}{ Exe. } & Concentric & $55.64 \pm 1.45$ & $59.64 \pm 1.65$ & $0.001^{*}$ \\
\hline & & Eccentric & $60.79 \pm 5.48$ & $65.20 \pm 6.96$ & $0.010^{*}$ \\
\hline \multirow{4}{*}{$\begin{array}{l}\text { Average peak } \\
\text { force } \\
\text { (N) }\end{array}$} & \multirow{2}{*}{ Con. } & Concentric & $50.65 \pm 3.40$ & $51.56 \pm 4.67$ & 0.196 \\
\hline & & Eccentric & $53.59 \pm 0.88$ & $51.96 \pm 0.62$ & 0.121 \\
\hline & \multirow[t]{2}{*}{ Exe. } & Concentric & $51.55 \pm 3.49$ & $54.65 \pm 4.47$ & $0.001^{*}$ \\
\hline & & Eccentric & $53.30 \pm 2.82$ & $55.81 \pm 4.86$ & $0.020^{*}$ \\
\hline \multirow{4}{*}{$\begin{array}{l}\text { Total work } \\
\text { (J) }\end{array}$} & \multirow[t]{2}{*}{ Con. } & Concentric & $383.64 \pm 128.20$ & $425.07 \pm 168.80$ & 0.233 \\
\hline & & Eccentric & $397.50 \pm 130.13$ & $417.64 \pm 164.39$ & 0.420 \\
\hline & \multirow[t]{2}{*}{ Exe. } & Concentric & $454.43 \pm 145.77$ & $553.00 \pm 168.34$ & $0.002^{*}$ \\
\hline & & Eccentric & $449.57 \pm 144.57$ & $548.36 \pm 168.52$ & $0.003^{*}$ \\
\hline
\end{tabular}

Values are means $\pm S D$.

${ }^{*} P<0.05$.

\section{DISCUSSION}

The elastic bands have been mainly used for in rehabilitation exercises for its inexpensive price, easy-to-install and safe properties while maintaining effective weight training capabilities. In his study, the PNF pattern was applied to an elastic band exercise, and we expected to find both the effectiveness of the elastic band and PNF pattern to enhance muscular strength. The elastic band exercise improves the muscular strength and explosive power (Docherty et al., 1998), the range of joint motion and flexibility (Brill et al., 1995), and walking ability and the daily activity capabilities (Tinetti et al., 1997). Hughes et al. (1999) reported a 12-week elastic band exercise program strengthened the knee joint extensor by 27 percent and muscles of lower extremities by 18 percent in the sample of seniors, while Klein et al. (2002) reported an increase of the ankle joint's bending power and walking rate with a 14-week exercise program. According to Jette et al. (1999), the walking ability and muscular strengths of the lower extremities were improved (by 6-12 percent) in a group of seniors who conducted 24 weeks of exercise. The results of studies directed toward the menopausal women also showing 9 to 21 percent increase in the quadriceps, knee joints and gripping power. Moreover, the results of bicycle ergometer test after applying the elastic band program in patients with Parkinson's disease showed a 24 percent improvement of the cardiovascular endurance as well as the overall quality of life including walking, muscle strength, posture and climbing the stairs (Levine et al., 2000).

Today, the effectiveness of the PNF is actively researched not only in light of the central nervous system disease, but also in the range of joint motion, pain, and stability of the joints; especially, in its application in the joint utilization (Jonghwan et al., 2003). Muscular strength training using the PNF pattern was effective in improving muscular strength, flexibility and balance. Its effectiveness in maximizing the exercise units by increasing coordination of the muscular strength, flexibility and responsiveness of the skeletal muscle system was confirmed. Consisting with other studies, our study also found significant increase within the experimental groups in muscular strength and peak power of the abductor of the lower extremities.

To summarize the results, the elastic band exercise can be utilized as a part of the rehabilitation program directed toward seniors or patients, in addition to normal healthy people along with athletes. If the PNF pattern applied elastic band exercise were to be conducted as a part of the training program, for example in soccer or cycling, which involves a lot of lower extremities power; it may 
not only increase the muscular strength but also improve stability of the hip and knee joints to prevent injuries. This will ultimately maximize results in performance. In the future, the effectiveness of PNF on the muscular strength can be explored independently by applying a non-PNF pattern elastic band exercise for the control group.

\section{CONFLICT OF INTEREST}

No potential conflict of interest relevant to this article was reported.

\section{REFERENCES}

Bongoh G, Miji K, Yonghyun K, Kyougyoon K, Mihyun K. Physical management for neurological conditions. Daehak Seorim 2013.

Brill PA, Drimmer AM, Morgan LA, Gordon NF. The feasibility of conducting strength and flexibility programs for elderly nursing home residents with dementia. Gerontologist 1995;35:263-266.

David BJ. Hollinshead's functional anatomy of the limbs and back. W.B. Saunders Company 2008.

Docherty CL, Moore JH, Arnold BL. Effects of strength training on strength development and joint position sense in functionally unsta- ble ankles. J Athl Train 1998;33:310-314.

Hughes CJ, Hurd K, Jones A, Sprigle S. Resistance properties of theraband tubing during shoulder abduction exercise. J Orthop Sports PhysTher 1999;29:413-420.

Song HS, Park SD, Kim JY. The effects of proprioceptive neuromuscular facilitation integration pattern exercise program on the fall efficacy and gait ability of the elders with experienced fall. J Exerc Rehabil 2014;10:236-240.

Jette AM, Lachman M, Giorgetti MM. Exercise-it's never too late: the strong for life program. Am J Pubilc Health 1999;89:66-72.

Jonghwan C, Chulhyun R, Kyumoon L, hyeonju K, Byeungok L. Effect of the PNF and weight training on flexibility, muscular strength, and power in college males. J Phys Growth Motor Dev 2003;11:35-43.

Klein DA, William JS, Wayne TP. PNF training and physical function in assisted-living older adults. J Aging Phys Act 2002;41:476-488.

Korea Institute of Sports Science. The latest exercise prescription. 21C education 1999.

Levine S, Brandenberg P, Pagel MA. Exercise program benefits of patients with mild to moderate parkinson's disease. Clin Exerc Physiol 2000; 2:43-48.

Tinetti ME, Liu WL, Claus EB. Predictors and prognosis of inability to get up after falls among elderly persons. JAMA 1993;269:65-70. 